\title{
Bacterial communities and their geochemical constrains in continental serpentinites from northern China
}

\author{
YAN LIU $^{1}$ XIANBIN WANG ${ }^{1 *}$ ZHIYONG HUANG $^{2}$ \\ ShengGuANG ZHUO ${ }^{3}$ XiAOLI YU ${ }^{1,4}$ JUNCHENG GONG $^{1}$ \\ HUI YANG ${ }^{1}$
}

${ }^{1}$ Key Laboratory of Petroleum Resources, Gansu Province / Northwest Institute of Eco-Environment and Resources, Chinese Academy of Sciences, Lanzhou 730000, PR China (*correspondence: xbwang@1zb.ac.cn)

${ }^{2}$ Tianjin Key Laboratory of Industrial Biological Systems and Bioprocessing Engineering, Tianjin Institute of Industrial Biotechnology, Chinese Academy of Sciences, Tianjin, 300308, PR China

${ }^{3}$ The School of Resource and Material, Northeastern University at Qinhuangdao, Qinhuangdao 066004, PR China

${ }^{4}$ University of Chinese Academy of Sciences, Beijing, 100049, PR China

Serpentinites are widely distributed in China. The process of serpentinization can produce raw materials, such as the fluids containing abundant molecular hydrogen and methane, for the chemosynthetic microorganisms to gain metabolic energy and to generate biomass. Microbial activities may also transform the composition and structure of the related rocks and ecosystems.

Clostridia, Betaproteobacteria, Alphaproteobacteria, Gammaproteobacteria, Bacilli and Actinobacteria were identified as the prominent members of the bacterial communities in the serpentinites from northern China by the 16S rRNA high-throughput sequencing. Clostridia and Betaproteobacteria have been reported in other serpentinitehosted microbiome in previous studies.

Abundant lizardite, chrysotile and antigorite were detected by XRD and SEM. Fe and $\mathrm{Cr}$ were widespread according to the element analysis, and they were considered to be the potential elements associated with the generation of hydrogen and methane. Further investigations on isotope composition of gas inclusions and carbonates as well as metagenomic identification would be continued. The total content of carbon $(<1.02 \%)$ was very low, so it was difficult to extract organic matter for biomarker analysis but worth trying. For the age-old serpentinites, it is very important to distinguish the information of serpentinization from the effects of diageneses and tectonism by geochemical characterization.

This study was supported by the National Natural Science Foundation of China (41272146; 41872146; 41972151). 